\title{
Development of a New Type of Alkali-Free Liquid Accelerator for Wet Shotcrete in Coal Mine and Its Engineering Application
}

\author{
Gang Zhou, ${ }^{1,2,3}$ Weimin Cheng, ${ }^{1,3}$ and Sen Cao ${ }^{1,3}$ \\ ${ }^{1}$ State Key Laboratory of Mining Disaster Prevention and Control Co-founded by Shandong Province and the Ministry of \\ Science and Technology, Shandong University of Science and Technology, Qingdao 266590, China \\ ${ }^{2}$ Key Laboratory of Safety and High-efficiency Coal Mining, Ministry of Education, Anhui University of Science and Technology, \\ Huainan 232001, China \\ ${ }^{3}$ College of Mining and Safety Engineering, Shandong University of Science and Technology, Qingdao 266590, China
}

Correspondence should be addressed to Gang Zhou; zhougang@sdust.edu.cn

Received 21 June 2015; Revised 4 August 2015; Accepted 4 August 2015

Academic Editor: Santiago Garcia-Granda

Copyright (c) 2015 Gang Zhou et al. This is an open access article distributed under the Creative Commons Attribution License, which permits unrestricted use, distribution, and reproduction in any medium, provided the original work is properly cited.

In order to address issues such as large rebound rate, high dust concentration, and low compressive strength of shotcrete when adding liquid accelerator during wet spraying, the factors influencing the efficiency of liquid accelerator were experimentally analyzed. The single-admixture, combination, and orthogonal tests were conducted on the five fundamental raw materials required to develop the new liquid accelerator. The WT-1 type liquid accelerator, which had better adaptability to different kinds of cement, was developed with the mass concentration ratio of $55 \%$ aluminum sulfate octadecahydrate, $4 \%$ sodium fluoride, $2.5 \%$ triethanolamine, $0.5 \%$ polyacrylamide, $5 \%$ bentonite, and $33 \%$ water. Experimental investigation showed that the initial setting time of the reference cement with $6 \%$ mass content of this liquid accelerator was 2 minutes and 15 seconds, and the final setting time was 7 minutes and 5 seconds. The compressive strength after 1 day of curing was $13.6 \mathrm{MPa}$ and the strength ratio after 28 days of curing was $94.8 \%$, which met the first grade product requirements of the China National Standard. Compared with the conventional type liquid accelerator, the proposed type WT-1 accelerator is capable of effectively reducing the rebound rate and dust concentration while significantly increasing the compressive strength of the shotcrete.

\section{Introduction}

As one of the key techniques to ensure the safety of an underground coal mine roof, anchor and spray support is widely employed in sinking and drifting engineering. Accelerator is a common additive in anchorage shotcrete which significantly reduces the time frame for concrete grout to consolidate, accelerates the hardening process of the cement, ensures the achievement of sufficient concrete strength in a short time frame, and reduces the rebound rate and improves productivity [1-3]. Since wet shotcrete has become increasingly popular in China's coal mines, the need for a liquid accelerator for underground anchors and spray support is of utmost importance.

The earliest liquid accelerator was the Sika accelerator developed decades ago in Sweden which was developed from a strong alkaline product to a low alkaline and finally to an alkali-free product and from a powder product to a liquid product $[4,5]$. The research on the development of low alkaline liquid accelerator began in the early 1990s, when the Nitto Chemical Industry Co. Ltd. synthetised an accelerator that contained alkali sulphate or carbonate and water-soluble aluminium salt or traces of magnesium carbonate [6]. This accelerator was capable of reducing the strength loss of concrete, but its adaptability to different types of cement and its workability were poor. In addition, the dust raised by its application and rebound rate was significant $[7,8]$. Burge synthetised a type of alkali-free liquid accelerator containing an aluminium salt, corrosion inhibitor, and complexing agent which produced concrete with compressive strengths at 1 day, 3 days, and 28 days of $19 \mathrm{MPa}, 32 \mathrm{MPa}$, and $48 \mathrm{MPa}$, respectively, but the setting time of concrete was longer [9]. MBT of Sweden produced the MEYCOSA series of alkali-free liquid accelerators which offered the advantages of high initial 
strength, low chlorine content, and low dust concentration during construction [10-12]. The research and development on an alkali-free liquid accelerator in China began in late 1990s and was rapid because of the outstanding advantages and requirement of shotcrete engineering in China. Pan and Lv of Nanjing Technological University successfully synthetised a type of NSA alkali-free liquid accelerator in using an inorganic-organic composition which exhibited no detrimental effects on the 28-day strength of the cement grout but adversely affected the initial strength $[13,14]$. The adaptability of the liquid accelerator to different types of cement was good. Ding et al. developed a type of DXQ alkali-free liquid accelerator which minimized strength loss at 28 days but did not appear to improve the initial strength [15]. In addition, the adaptability to various types of cement and temperature was poor and the 28-day strength ratios of different types of cement scattered significantly [16]. Han et al. developed a type JL-1 low alkaline liquid accelerator using sulphur aluminate and neutral sodium salt as coagulant and optimised the product using polymer [17]. This accelerator effectively reduced the rebound rate and the strength loss at 28 days was minimal. It was beneficial to the durability of concrete, but the performance was considerably affected by different water-cement ratios and types of cement.

In summary, a variety of mixed results were obtained by a number of researchers seeking developing a suitable liquid accelerator for shotcrete. However, due to the rigorous environmental conditions in underground coal mines, problems with the development of shotcrete persist. These include low durability, low long-term strength, large rebound rates and dust concentration, poor adaptability for various types of cement, and corrosive damage. These problems significantly affect the health of the workers and the quality of the projects and hinder the promotion of wet shotcreting in mines. Since the dry concrete spraying machine has been listed as outdated and prohibited by the State Administration of Work Safety, rapid development of the wet shotcreting technique in mines of China is imminent. Therefore, it is of particular interest to develop a liquid shotcrete accelerator that is highly efficient, economical, and environmentally friendly.

\section{Experimental Materials and Program}

\subsection{Experimental Materials}

2.1.1. Cement. The reference cement is the special cement for testing the performance of concrete admixture, which has a strength level exceeding 42.5. No composite material is added. Moreover, the contents of main components of reference cement are shown in Table 1.

2.1.2. Sand. The sand used in these experiments was standard sand employed in strength tests of cement which complies with the requirements of the ISO standard in national standard GB/T17671-1999 Method of testing cementsDetermination of strength.

2.1.3. Constituents of the New Type of Liquid Accelerator. Based on the literature review of domestic and international
TABLE 1: Contents of main components of reference cement.

\begin{tabular}{lccc}
\hline $\begin{array}{l}\text { Tricalcium } \\
\text { aluminate }\end{array}$ & $\begin{array}{c}\text { Tricalcium } \\
\text { silicate }\end{array}$ & $\begin{array}{c}\text { Free } \\
\text { calcium } \\
\text { oxide }\end{array}$ & $\begin{array}{c}\text { Alkali } \\
\text { content }\end{array}$ \\
\hline $6-8 \%$ & $55-60 \%$ & $\leqslant 1.2 \%$ & $\leqslant 1 \%$ \\
\hline
\end{tabular}

studies of accelerators, an initial selection experiment was conducted on a large range of materials [16, 18-21]. Finally five types of chemical raw materials apart from water have been determined, which are represented as A, B, C, D, and E, among which $\mathrm{A}$ is the major component of the accelerator.

Specifically, Material A is aluminum sulfate octadecahydrate which is the main coagulating constituent of the new type accelerator containing $51.4 \%$ anhydrous aluminum sulfate. According to the related information, the aluminum ion can accelerate the solidification process of cement when added into it. Moreover, the solidification time will reduce greatly with the increasing in the amount of aluminum ion [22-26]. From the above it can be known that aluminum sulfate is an ideal component of accelerator, for it is alkali-free but has good coagulating effect.

Material B is sodium fluoride, a kind of metal fluoride in a solid powder state at room temperature with relatively low solubility. The addition of single component B cannot reduce the solidification time for cement obviously. However, Material B is a kind of effective complexing agent. When A mixes with $\mathrm{B}$, a relatively stable material, sodium hexafluoroaluminate, is generated, which can increase the amount of aluminum ion. The adding of mixture of A and B into cement can accelerate the formation speed of hydrate effectively, and the cement can be coagulated quickly; then the strength and stability of sprayed concrete can be improved in a short time.

Material C is triethanolamine, an organic alkamine-typed accelerator in a liquid state at room temperature which is highly soluble in water, and it is nontoxic. As a kind of catalytic agent, Material C can improve the solubility of aluminum sulfate and increase the amount of aluminum ion in the accelerator solution, and the coagulating speed of cement can be improved in this way.

Material D is polyacrylamide, a linear high molecular weight polymer, and it is nontoxic. As a kind of good binder, a small amount of Material D can improve the cohesion of cement paste. Besides, Material D can also lock moisture and help coagulant components shorten solidification time, so it is a good synergist.

Material $\mathrm{E}$ is bentonite, a soil-state mineral with extremely small diameter of particle which is nontoxic and inexpensive. Material E plays an important role in the new-type accelerator. Firstly, Material E shows good cohesiveness after mixing with water because of its good hydrophilicity, which is useful in reducing the rebound rate and dust concentration in the wet spraying field. Secondly, Material E has great properties of suspension and dispersion, so it can work as a kind of thickening agent in the accelerator solution to improve the stability of liquid. Thirdly, Material E has large expansion coefficient and its volume can expand to 40 times as before after absorbing water, which can reduce 
the cracked phenomenon due to the volume shrinkage of cement.

2.1.4. Existing Accelerator. In order to analyse the factors affecting the coagulating performance of the accelerator, a standard liquid accelerator produced by Jiangsu Bote New Materials Co. Ltd. was used in the experiments.

\subsection{Experimental Program}

2.2.1. Standard of Evaluation of Accelerator. The industrial standard of building materials in China JC477-2005 Flashing Setting Admixtures for Shotcrete specifies the requirements of performance for an accelerator-added cement paste and hardened mortar, as shown in Table 2.

2.2.2. Measurement of Setting Time for Cement Paste. The setting time of cement paste is the primary performance indicator of an accelerator since a setting time that is too short significantly undermines the normal hydration process of concrete and affects the stability of the structure, while a setting time that is too long leads to large rebound rate, which reduced thickness of each layer of shotcrete and difficulty in curing the concrete [27-29]. The Vicat apparatus was used to measure the performance of accelerator.

\subsubsection{Measurement of Strength of the Sand-Cement Grout.} The strength of sand-cement grout was measured using a WDW3100 computer-controlled electric universal test machine. Mould with a dimension of $40 \mathrm{~mm} \times 40 \mathrm{~mm} \times$ $160 \mathrm{~mm}$ and standard curing box were used.

\section{Experimental Analysis of Impact Factors of the Coagulating Performance of Accelerator}

The setting time of an accelerator and the strength of the product at different ages are affected by a number of factors including the method of operation, amount of accelerator added, and temperature of the material. Therefore, it is necessary to analyse the primary impact factors in order to unify the test methods to acquire accurate results. The reference cement and alkali-free liquid accelerator produced by Bote were used in the control experiments.

3.1. Effect of Material Temperature. Despite the fact that the shotcreting temperature should be controlled at $20^{\circ} \mathrm{C} \pm 2^{\circ} \mathrm{C}$ as specified by JC477-2005 Flashing Setting Admixtures for Shotcrete, considering the actual conditions in coal mines, the effect of material temperature on the result of solidification at an environmental temperature of $20^{\circ} \mathrm{C}$ was tested, as shown in Figure 1.

It could be seen from the test results that, with the increase in temperature of the material, the setting time decreased gradually, which was caused by the increase in reaction speed of hydration between cement, accelerator, and water in condition that the temperature of the material increased. After the temperature of the material increased to $15^{\circ} \mathrm{C}$,

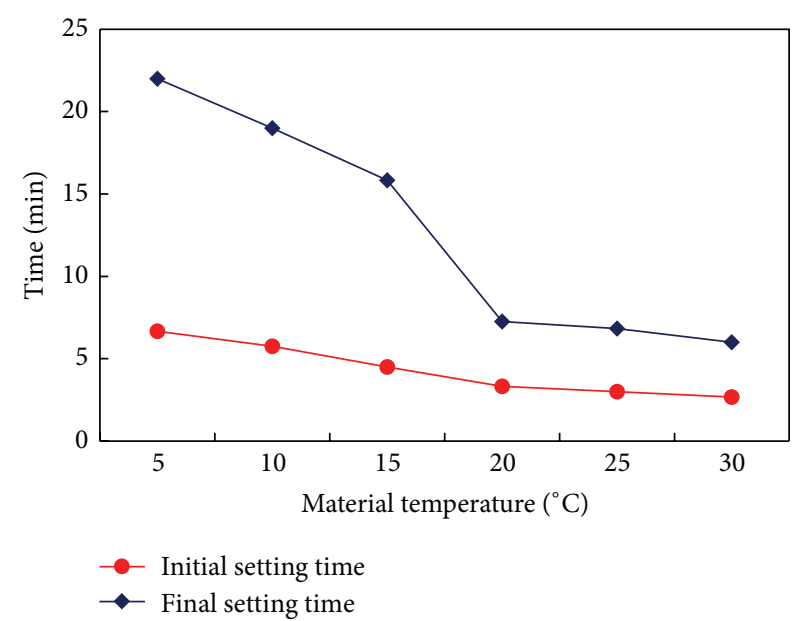

FIgURE 1: Effect of material temperature on the result of solidification at an environmental temperature of $20^{\circ} \mathrm{C}$.

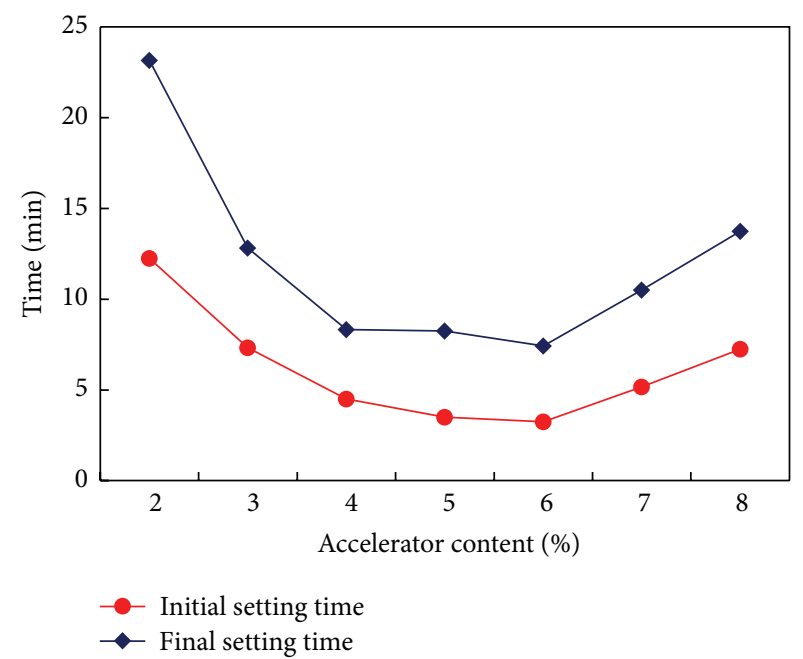

FIgURE 2: Effect of accelerator mass content on setting time.

the hydration reaction released a lot of heat in a short time, which significantly reduced the final setting time of concrete. These results indicated that, during shotcreting, insulation should be implemented. During the experiment to develop a new type of liquid accelerator used in mines, the environmental as well as material temperature was controlled at $20^{\circ} \mathrm{C}$.

3.2. Effect of the Content of Accelerator on the Setting Time of Cement. At a fixed test temperature of $20^{\circ} \mathrm{C}$ of both environment and material, the effect of various accelerator concentrations on the setting time of the reference cement is shown in Figure 2.

According to Figure 2, during the process that content of accelerator increased from $2 \%$ to $6 \%$, the initial setting time reduced from $12 \mathrm{~min}$ to $3 \mathrm{~min}$ and the final setting time reduced from $23 \mathrm{~min}$ to $7 \mathrm{~min}$. The final setting time did not change generally when the content of accelerator was $4 \%$ and $5 \%$, while when the content of accelerator gradually increased 
TABLE 2: Performance requirements of cement paste and cement mortar mixing accelerator.

Test items

\begin{tabular}{lcccc} 
Product rating & \multicolumn{2}{c}{ Cement paste } & \multicolumn{2}{c}{$\begin{array}{c}\text { Cement mortar } \\
\text { Compressive strength ratio } \\
\text { of 28 days/\% }\end{array}$} \\
\hline First grade & Initial setting time/min & Final setting time/min & $\begin{array}{c}\text { Compressive strength of } \\
\text { one day/MPa }\end{array}$ & $\begin{array}{c}\text { ond } \\
\text { Qualified product }\end{array}$ \\
\hline
\end{tabular}

TABLE 3: Effects of mixing time on setting time under the same test conditions.

\begin{tabular}{lcccc}
\hline $\begin{array}{l}\text { Accelerator } \\
\text { mass } \\
\text { content/\% }\end{array}$ & $\begin{array}{c}\text { Mixing } \\
\text { time/s }\end{array}$ & $\begin{array}{c}\text { Initial setting } \\
\text { time/min }\end{array}$ & $\begin{array}{c}\text { Final setting } \\
\text { time/min }\end{array}$ & $\begin{array}{c}\text { Test } \\
\text { error/s }\end{array}$ \\
\hline & 5 & 4.5 & 11.2 & $>15$ \\
& 8 & 3.2 & 7.3 & $<10$ \\
6 & 12 & 3.8 & 7.7 & $<10$ \\
& 15 & 4.9 & 13.2 & $<5$ \\
& 20 & 8.5 & 15.0 & $<5$ \\
& 30 & 14.8 & 30.2 & $<5$ \\
\hline
\end{tabular}

from $6 \%$ to $8 \%$, setting time increased. The initial setting time increased from $3 \mathrm{~min}$ when content was $6 \%$ to $7 \mathrm{~min}$ when content was $8 \%$, and the final setting time increased from $7 \mathrm{~min}$ to $14 \mathrm{~min}$.

It could be seen that there is an optimum value for the accelerator concentration and an ideal coagulating effect cannot be achieved when the content is too small or large. Therefore, the optimum accelerator content should be used to minimize its waste and the long-term strength loss of the concrete. Based on practical and empirical findings, the mass content of accelerator was identified as $6 \%$ during the experiment to develop a new type of liquid accelerator used in mines.

\subsection{Effects of Experimental Operating Methods}

3.3.1. Effect of Mixing Time. The effect of different mixing time on the performance of the accelerator under the same experimental conditions was determined and the results are shown in Table 3.

It can be seen from Table 3 that the mixing time significantly affected the concrete setting time. When the mixing time was less than 5 seconds, the liquid accelerator did not evenly disperse in the cement grout. The reproducibility of multiple trials was poor and error was significant. When the mixing time was increased to $8-12$ seconds, the initial setting time, final setting time, and experimental errors were significantly reduced and the effect of solidification was outstanding. When the mixing time was increased to 15 seconds, the setting time increased dramatically. This was due to the fact that the hydration mesh structure in cement could be formed in an instant after the accelerator was added to the cement; at the same time, the effective components of accelerator were also in constant consumption; continuous
TABLE 4: Effect of vibration frequency on setting time under the same test conditions.

\begin{tabular}{lcccc}
\hline $\begin{array}{l}\text { Accelerator } \\
\text { mass } \\
\text { content/\% }\end{array}$ & $\begin{array}{c}\text { Vibration } \\
\text { frequency }\end{array}$ & $\begin{array}{c}\text { Initial } \\
\text { setting } \\
\text { time/min }\end{array}$ & $\begin{array}{c}\text { Final setting } \\
\text { time/min }\end{array}$ & $\begin{array}{c}\text { Test } \\
\text { error/s }\end{array}$ \\
\hline & 0 & 4.8 & 7.0 & $>10$ \\
& 3 & 3.4 & 7.3 & $<10$ \\
6 & 5 & 3.3 & 7.7 & $<5$ \\
& 10 & 3.5 & 8.3 & $<5$ \\
& 20 & 4.0 & 10.0 & $<5$ \\
& 30 & 4.4 & 12.5 & $<5$ \\
\hline
\end{tabular}

stirring and the resulting shock destroyed these structures, leading to longer setting time. During field application, when concrete was pressed into the high pressure spray hose, the accelerator was added into the concrete with adding device at the same time, and there is no mixing process.

Therefore, in view of the influence of above mixing time on the coagulating performance of the accelerator, taking the actual situation into consideration, the mixing time during the experiment was set to around 8 seconds just to ensure that the accelerator is completely mixed with the cement grout.

3.3.2. Effect of Frequency of Vibration. The setting speed increased dramatically when the accelerator was added to the cement grout and the liquidity of cement grout was lost after mixing, so that hand or machine vibration was required during moulding process. Therefore, in the condition that the mixing time was 8 seconds, the effect of the vibration frequency on the performance of the accelerator was measured and the results are shown in Table 4.

It can be seen from the experimental results that when compared with mixing time, the effect of vibration frequency was smaller but not negligible. Delay in setting time would occur without vibration or with excessive vibration. Therefore, the frequency of vibration was set at 5 .

\section{Results and Discussions}

\subsection{Preparation of Mother Liquor for the New Type of Liquid Accelerator}

4.1.1. Single-Admixture of Material A. Because Material A is the primary coagulating ingredient of the new accelerator, it is necessary to experimentally determine its optimum concentration range. An aqueous solution of Material A with 
TABle 5: Aluminum sulfate octadecahydrate solubility.

\begin{tabular}{lccccccccccc}
\hline Temperature $/{ }^{\circ} \mathrm{C}$ & 0 & 10 & 20 & 30 & 40 & 50 & 60 & 70 & 80 & 90 & 100 \\
\hline Solubility $/(\mathrm{g} / 100 \mathrm{~mL})$ & 31.2 & 33.5 & 36.5 & 40.4 & 45.7 & 52.2 & 59.2 & 66.2 & 73.1 & 86.8 & 89.0 \\
\hline
\end{tabular}

TABLE 6: Effects of aluminum sulfate mass content on the setting time and strength of cement.

\begin{tabular}{lcccccc}
\hline $\begin{array}{l}\text { Content of } \\
\text { Material A/\% }\end{array}$ & $\begin{array}{c}\text { Content of } \\
\text { aluminum } \\
\text { sulfate/\% }\end{array}$ & $\begin{array}{c}\text { Initial setting } \\
\text { time/min }\end{array}$ & $\begin{array}{c}\text { Final setting } \\
\text { time/min }\end{array}$ & $\begin{array}{c}\text { Compressive strength } \\
\text { of one day/MPa }\end{array}$ & $\begin{array}{c}\text { Compressive strength } \\
\text { of 28 days/MPa }\end{array}$ & $\begin{array}{c}\text { Compressive } \\
\text { strength ratio of 28 } \\
\text { days/\% }\end{array}$ \\
\hline 0 & 0 & 195 & 258 & 7.8 & 43.9 & 100 \\
35 & 18 & 120 & 195 & 8.1 & 40.5 & 38.1 \\
45 & 23 & 98 & 174 & 8.4 & 35.8 & 87 \\
55 & 28 & 81 & 159 & 9.6 & 34.2 & 78 \\
65 & 33 & 79 & 152 & 9.8 & 32.0 & 73 \\
75 & 39 & 77 & 147 & 9.3 & & 73 \\
\hline
\end{tabular}

a concentration ranging from 0 to $75 \%$ was prepared and used directly as an accelerator to measure the setting time and strength with the addition content held at $6 \%$. The solubility and content of Material A on the setting time and strength of cement are shown in Tables 5 and 6.

As can be seen from the test results summarized in Tables 5 and 6

(1) with the increase in the content of $A$, the initial and final setting time decreased; however, the setting time did not change when the content of A exceeded 55\%; at $20^{\circ} \mathrm{C}$, the solubility of aluminium sulphate was only $36.5 \mathrm{~g}$; that is, the saturated concentration was 26.7\%; however, when the content of A reached 55\%, the content of aluminium sulphate in the solution was $28 \%$ which exceeded the saturated concentration; therefore, the setting time will not decrease even when the content of A increases;

(2) with the increase in the content of A, the compressive strength after 1 day increased and the increasing was most significant when the content of A was below 55\%; however, the strength after 28 days decreased; this result was caused by the addition of $\mathrm{A}$ which introduced bivalent sulphate ion which reacted with calcium hydroxide to produce dihydrate gypsum; although the gypsum improves the initial strength, expansive calcium sulphoaluminate is produced continuously which leads to a reduction of long-term strength.

Concluding from the test analysis of setting time and strength, the optimum content of $\mathrm{A}$ in the solution is $55 \%$, which is $3.3 \%$ of the mass of the cement.

4.1.2. Combination of Materials $A$ and B. According to the preliminary test results, Material B had a better effect of complexation with the mass content of $3 \%$ to $5 \%$. Therefore, the content of Material A was set as $55 \%$ for combination with various amounts of Material B. The content of the accelerator was held at $6 \%$ and the setting time and strength were measured and results are shown in Table 7.
As can be seen from the test results in Table 7

(1) the setting time was significantly reduced with the increase of the content of B; when the content of B was around $4 \%$, the effect of solidification was the optimum; however, the setting time appeared to increase as the concentration of Material B kept increasing which suggests that the addition of an appropriate amount of Material B improves the coagulating effect of the accelerator;

(2) the addition of an appropriate amount of Material B not only effectively increases the short-term speed of the hydration of cement leading to an increase of compressive strength at 1 day, but also increases the compressive strength at 28 days; the increase of compressive strength at 28 days exceeded $100 \%$ when the content of Material B in the mixture was $4.5 \%$.

In conclusion, the content of Material B in the solution should be kept at $3.5 \%$ to $4.5 \%$ which takes $0.21 \%$ to $0.27 \%$ of the mass of cement.

4.1.3. Combination of Materials $A$ and $C$. According to the preparatory study, material $C$ had a better effect of solidification with the mass content below 3\%. Similarly, the content of Material A in the mixture was set as 55\% for combination with various amounts of Material $\mathrm{C}$. The setting time and strength with the addition of $6 \%$ of the accelerator were measured and results are shown in Table 8.

As can be seen from the test results in Table 8

(1) the addition of Material C improved the coagulating effect of aluminium sulphate; when the content of $\mathrm{C}$ in the solution was $2 \%$ to $3 \%$, the speed of hydration of the cement significantly increased and the initial setting time was reduced to below 50 minutes; however when the content of $\mathrm{C}$ exceeded $2.5 \%$, the setting speed decreased, which suggests that the amount of Material $\mathrm{C}$ in the accelerator should be limited;

(2) in a similar manner to Material B, the addition of $\mathrm{C}$ increased the compressive strength of the concrete 
TABLE 7: Experimental results of combination of Materials A and B.

\begin{tabular}{|c|c|c|c|c|c|c|}
\hline $\begin{array}{l}\text { Content of } \\
\text { Material A/\% }\end{array}$ & $\begin{array}{c}\text { Content of } \\
\text { Material B/\% }\end{array}$ & $\begin{array}{l}\text { Initial setting } \\
\text { time } / \mathrm{min}\end{array}$ & $\begin{array}{l}\text { Final setting } \\
\text { time } / \mathrm{min}\end{array}$ & $\begin{array}{l}\text { Compressive } \\
\text { strength of one } \\
\text { day/MPa }\end{array}$ & $\begin{array}{c}\text { Compressive } \\
\text { strength of } 28 \\
\text { days } / \mathrm{MPa} \\
\end{array}$ & $\begin{array}{l}\text { Compressive strength } \\
\text { ratio of } 28 \text { days } \% \%\end{array}$ \\
\hline \multirow[t]{3}{*}{0} & 0 & 195 & 258 & 7.8 & 43.9 & 100 \\
\hline & 0 & 90 & 162 & 9.1 & 37.8 & 86 \\
\hline & 3 & 51 & 101 & 10.3 & 40.5 & 92 \\
\hline \multirow[t]{4}{*}{55} & 3.5 & 29 & 79 & 10.7 & 41.1 & 94 \\
\hline & 4 & 22 & 52 & 11.2 & 42.8 & 97 \\
\hline & 4.5 & 24 & 59 & 10.3 & 44.0 & 100 \\
\hline & 5 & 25 & 60 & 9.5 & 45.2 & 103 \\
\hline
\end{tabular}

TABLE 8: Experimental results of combination of Materials A and C.

\begin{tabular}{|c|c|c|c|c|c|c|}
\hline $\begin{array}{l}\text { Content of } \\
\text { Material A/\% } \\
\end{array}$ & $\begin{array}{c}\text { Content of } \\
\text { Material C/\% }\end{array}$ & $\begin{array}{c}\text { Initial setting } \\
\text { time/min }\end{array}$ & $\begin{array}{c}\text { Final setting } \\
\text { time/min }\end{array}$ & $\begin{array}{c}\text { Compressive strength } \\
\text { of one day/MPa }\end{array}$ & $\begin{array}{c}\text { Compressive strength } \\
\text { of } 28 \text { days } / \mathrm{MPa}\end{array}$ & $\begin{array}{c}\text { Compressive strength } \\
\text { ratio of } 28 \text { days } / \%\end{array}$ \\
\hline \multirow[t]{3}{*}{0} & 0 & 195 & 258 & 7.8 & 43.9 & 100 \\
\hline & 0 & 90 & 162 & 9.1 & 37.8 & 86 \\
\hline & 1 & 69 & 124 & 9.7 & 39.9 & 91 \\
\hline \multirow[t]{4}{*}{55} & 1.5 & 59 & 104 & 10.3 & 41.5 & 95 \\
\hline & 2 & 48 & 86 & 11.2 & 42.3 & 96 \\
\hline & 2.5 & 41 & 80 & 11.1 & 42.8 & 97 \\
\hline & 3 & 47 & 85 & 10.8 & 43.1 & 98 \\
\hline
\end{tabular}

after 1 day of curing; when the content of $\mathrm{C}$ was $2 \%$, the compressive strength after the 1-day curing reached the maximum value of $11.2 \mathrm{MPa}$, but it decreased when the amount of $\mathrm{C}$ exceeded $2 \%$; as the amount of $\mathrm{C}$ was increased, the compressive strength after 28-day curing increased, which suggests that the addition of $\mathrm{C}$ helps to compensate for the loss of strength incurred by the presence of aluminium sulphate; when the content of C exceeded $1.5 \%$, the strength ratio at the 28 -day cure was above $95 \%$.

In summary, the optimum content of Material $\mathrm{C}$ in the solution was $2 \%$ to $3 \%$, which amounts to $0.12 \%$ to $0.18 \%$ of the mass of cement.

4.1.4. Orthogonal Matching Tests. The optimum range for the concentration of the three additive materials was determined from single-admixture of aluminium sulphate and the combination of aluminium sulphate with Materials B and C. However, the mechanism of the effect on the hydration process of cement is different and the effect of the combined action of the three materials is unknown. In order to evaluate the optimum admixture of the combination of the three materials, it was necessary to determine the concrete materials' properties when adding all of the materials simultaneously. In order to simplify the experiment, $\mathrm{A}, \mathrm{B}$, and $\mathrm{C}$ were selected as the three primary factors and orthogonal tests were conducted on three levels in which A was tested at $50 \%$, $55 \%$, and $60 \%$ and $\mathrm{B}$ at $3.5 \%, 4 \%$, and $4.5 \%$, while $\mathrm{C}$ was presented at $2 \%, 2.5 \%$, and $3 \%$, as shown in Table 9 .
TABLE 9: Orthogonal test proposal.

\begin{tabular}{lccc}
\hline Test number & $\begin{array}{c}\text { Content of } \\
\text { Material A/\% }\end{array}$ & $\begin{array}{c}\text { Content of } \\
\text { Material B/\% }\end{array}$ & $\begin{array}{c}\text { Content of } \\
\text { Material } \\
\text { C/\% }\end{array}$ \\
\hline 1 & 50 & 3.5 & 2 \\
2 & 50 & 4 & 2.5 \\
3 & 50 & 4.5 & 3 \\
4 & 55 & 3.5 & 2.5 \\
5 & 55 & 4 & 3 \\
6 & 55 & 4.5 & 2 \\
7 & 60 & 3.5 & 3 \\
8 & 60 & 4 & 2 \\
9 & 60 & 4.5 & 2.5 \\
\hline
\end{tabular}

The setting time and strength for each group were measured according to orthogonal matching and the results are shown in Figures 3 and 4.

To better demonstrate the effects of $\mathrm{A}, \mathrm{B}$, and $\mathrm{C}$ in the mother liquor, range analysis was conducted on the results of orthogonal matching tests as shown in Table 10.

It can be seen from the results of orthogonal matching tests in Table 10 that

(1) the effect of combining A, B, and C was evident; not only did the setting time in most cases meet the requirement of a qualified accelerator dictated by JC477-2005 Flashing Setting Admixtures for Shotcrete, but the compressive strength ratio at 
TABLE 10: Range analysis of the main components in mother liquor.

\begin{tabular}{|c|c|c|c|c|}
\hline Determination items & A & B & $\mathrm{C}$ & $\begin{array}{l}\text { Factors sorting and } \\
\text { optimal group }\end{array}$ \\
\hline \multicolumn{5}{|l|}{ Setting time } \\
\hline \multicolumn{5}{|l|}{ Initial setting time/s } \\
\hline Mean value 1 & 241.7 & 243.3 & 230.0 & \multirow{4}{*}{$\begin{array}{l}\text { Factors sorting: } \mathrm{BAC} \\
\text { Optimal group: } \mathrm{A}_{2} \mathrm{~B}_{2} \mathrm{C}_{3}\end{array}$} \\
\hline Mean value 2 & 220.0 & 213.3 & 240.0 & \\
\hline Mean value 3 & 235.0 & 240.0 & 226.7 & \\
\hline Range & 21.7 & 30 & 13.3 & \\
\hline \multicolumn{5}{|l|}{ Final setting time/s } \\
\hline Mean value 1 & 566.7 & 570.0 & 558.3 & \multirow{4}{*}{$\begin{array}{l}\text { Factors sorting: } \mathrm{BAC} \\
\text { Optimal group: } \mathrm{A}_{2} \mathrm{~B}_{2} \mathrm{C}_{3}\end{array}$} \\
\hline Mean value 2 & 530.0 & 516.7 & 550.0 & \\
\hline Mean value 3 & 555.0 & 565.0 & 543.3 & \\
\hline Range & 36.7 & 53.3 & 15.0 & \\
\hline \multicolumn{5}{|l|}{ Compressive strength } \\
\hline \multicolumn{5}{|c|}{ Compressive strength of one day/MPa } \\
\hline Mean value 1 & 12.5 & 11.0 & 11.1 & \multirow{4}{*}{$\begin{array}{l}\text { Factors sorting: } A B C \\
\text { Optimal group: } A_{1} B_{2} C_{3}\end{array}$} \\
\hline Mean value 2 & 11.6 & 11.6 & 11.2 & \\
\hline Mean value 3 & 9.5 & 11.1 & 11.3 & \\
\hline Range & 3.0 & 0.6 & 0.2 & \\
\hline \multicolumn{5}{|c|}{ Compressive strength of 28 days/MPa } \\
\hline Mean value 1 & 44.8 & 42.1 & 42.6 & \multirow{4}{*}{$\begin{array}{l}\text { Factors sorting: } A B C \\
\text { Optimal group: } A_{1} B_{3} C_{3}\end{array}$} \\
\hline Mean value 2 & 42.6 & 42.8 & 43.1 & \\
\hline Mean value 3 & 41.5 & 44.1 & 43.2 & \\
\hline Range & 3.3 & 2.0 & 0.6 & \\
\hline
\end{tabular}

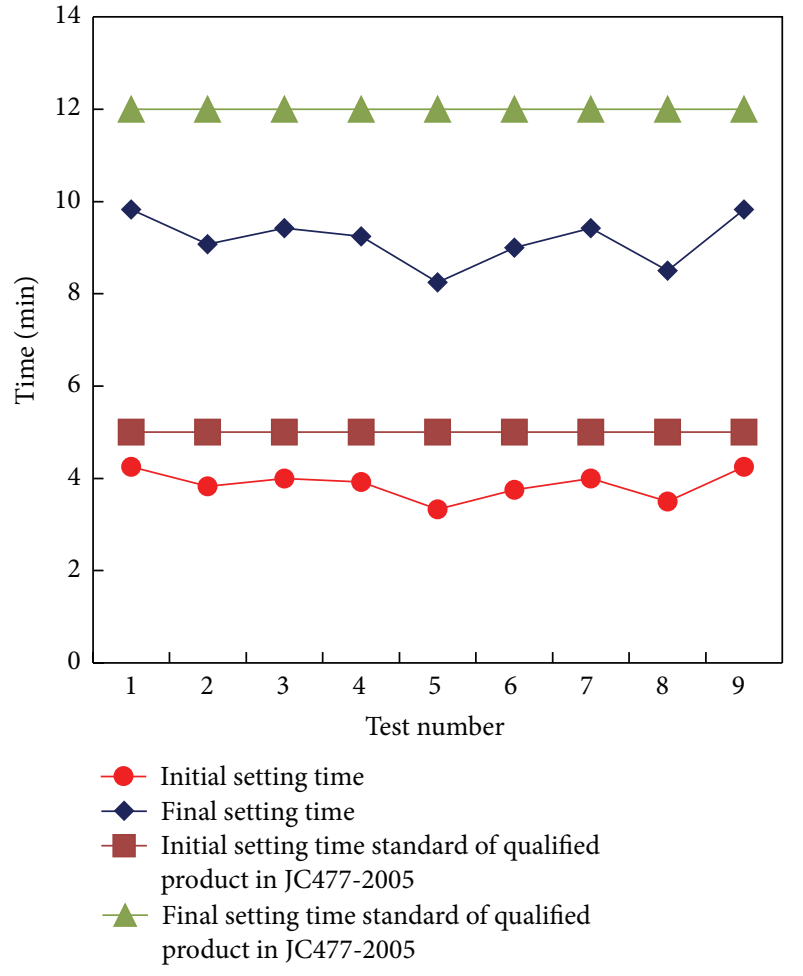

Figure 3: Setting time of orthogonal test.

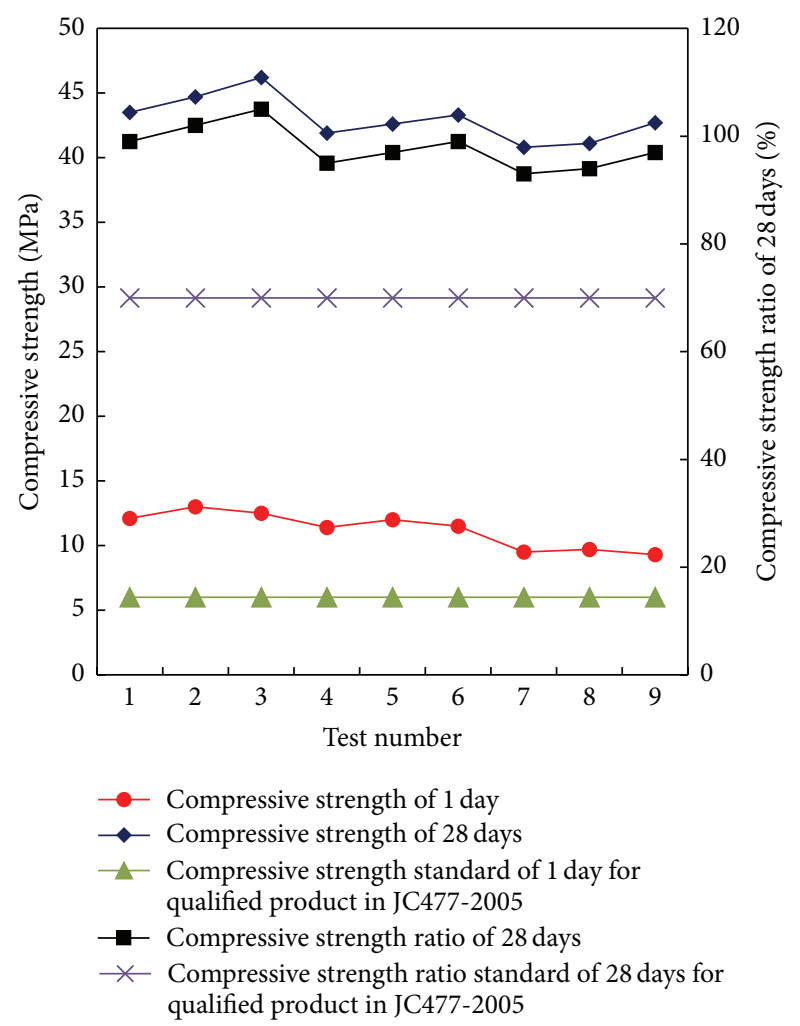

FIGURE 4: Compressive strength of orthogonal test. 
28 days was also above 93\%, which exceeds the requirement for a first grade accelerator which is $75 \%$;

(2) it is evident from the results of range analysis that the sequence of significance for the three materials in terms of initial and final setting time was $\mathrm{B}>$ A > C; in terms of compressive strength at 1 day and compressive strength at 28 days, the sequence was $\mathrm{A}>\mathrm{B}>\mathrm{C}$; an improvement effect in setting time can be achieved by adjusting Material B, while an improvement in strength can be achieved by adjusting Material A; Material $\mathrm{C}$ appears to play a supplementary role;

(3) the mother liquor of the new accelerator is good in terms of developed compressive strength, but it did not meet the requirement of a first grade accelerator in terms of setting time; therefore, further optimization of the mother liquor is required to reduce the setting time.

In conclusion, the formula of the mass content for each material in mother liquor is Material A: $55 \%$; Material B: $4 \%$; Material C: $2.5 \%$, and the remainder is water. According to the content of accelerator in cement, Materials A, B, and C constitute $3.3 \%, 0.24 \%$, and $0.15 \%$ of the final mass of cement, respectively.

4.2. Optimum Combination for the Mother Liquor of the Accelerator. To further reduce the concrete setting time, improve the viscosity of the new accelerator, and reduce the rebound rate, testing was conducted to optimize the mother liquor by combining with Materials D and E. Initial tests determined that, with Material D at $0.2 \%$ to $0.6 \%$ and Material $\mathrm{E}$ at $3 \%$ to $7 \%$ in the accelerator, the modified accelerator exhibited outstanding viscosity and the performance of the accelerator was excellent.

Because Materials D and E play the roles of solidification and viscosity enhancement in the new accelerator mainly and their impacts on the strength of cement mortar are small, optimizing tests of the mother liquid with Materials D and E were conducted without strength tests and the strength was measured after the optimized formula was determined.

In addition, since the cement grout hardens rapidly after the addition of accelerator, the viscosity is difficult to measure. The viscosity of the accelerator itself cannot accurately reflect the viscosity of concrete after the addition of the accelerator. Therefore, the viscosity was estimated by observation.

4.2.1. Modification of Mother Liquid by Combination with Material D. When D was added to the mother liquid with a specified content ratio of $0.2 \%$ to $0.6 \%$ in the combination solution, the setting time was measured at an accelerator concentration of $6 \%$. The setting time of cement grout when the mother liquid was combined with Material D is shown in Figure 5.

It can be seen from the experimental results and observations that

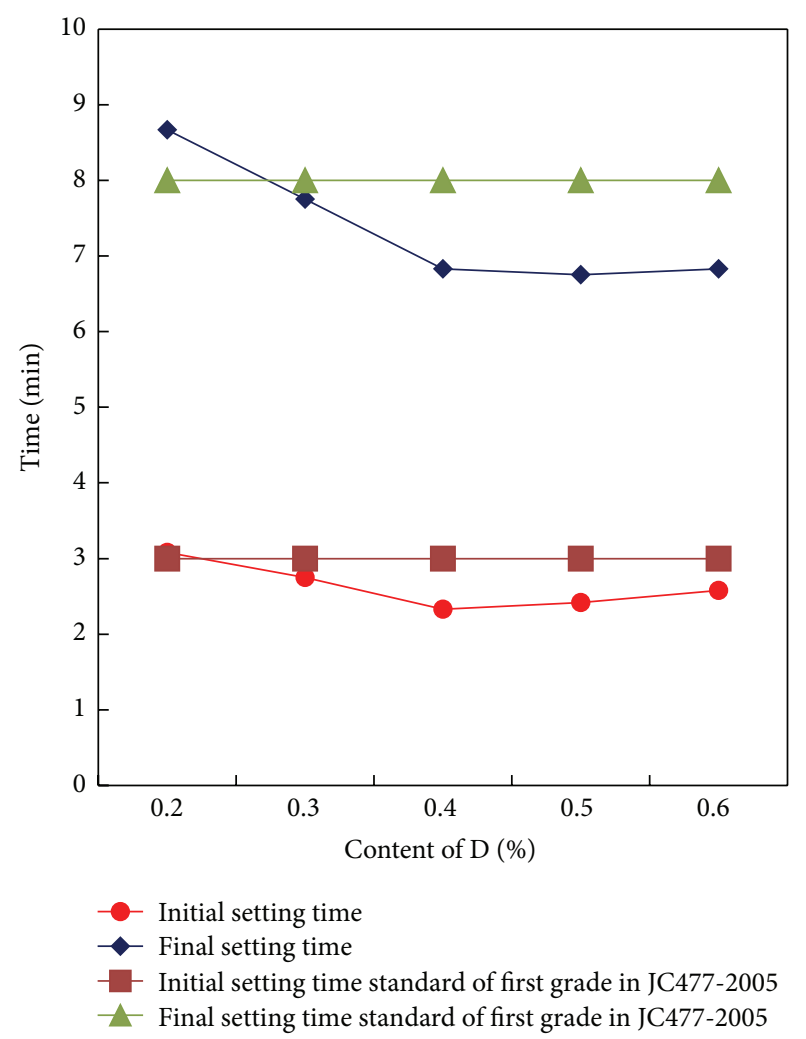

FIGURE 5: Setting time of cement grout mixing with mother liquid and Material D.

(1) the addition of D further improved the coagulating effect of the accelerator; in addition to the case when the content of $\mathrm{D}$ was $0.2 \%$, the requirement of a first grade accelerator was met in terms of setting time; in particular, the coagulating effect was the optimum when the content of $\mathrm{D}$ was $0.4 \%$ to $0.5 \%$ in which the initial setting time was the shortest when the content was $0.4 \%$ and the final setting time was the shortest when the content was $0.5 \%$;

(2) it was observed from the tests that the addition of $\mathrm{D}$ to the mother liquid improved the viscosity; when added to the cement grout, the viscosity of the grout was improved dramatically and the viscosity enhancement was the optimum when the content of $\mathrm{D}$ was $0.5 \%$; further increases in the content of $\mathrm{D}$ led to overwhelmed viscosity of the accelerator and resistance of the mixture during transport increased; therefore, the optimum content of $\mathrm{D}$ was set at $0.5 \%$.

4.2.2. Combination of the Modified Mother Liquor with Material E. A solution of $61.5 \%$ content with the mother liquid and $0.5 \%$ with Material D was used for the optimum combination experiments with Material E. The characteristics of E were fully utilized to further improve the stability of the solution and viscosity and durability of the concrete. The content of $\mathrm{E}$ during combination tests was 3\% to $7 \%$. The setting time was measured and the viscosity of cement grout was estimated by observation. The setting time of the cement grout when 


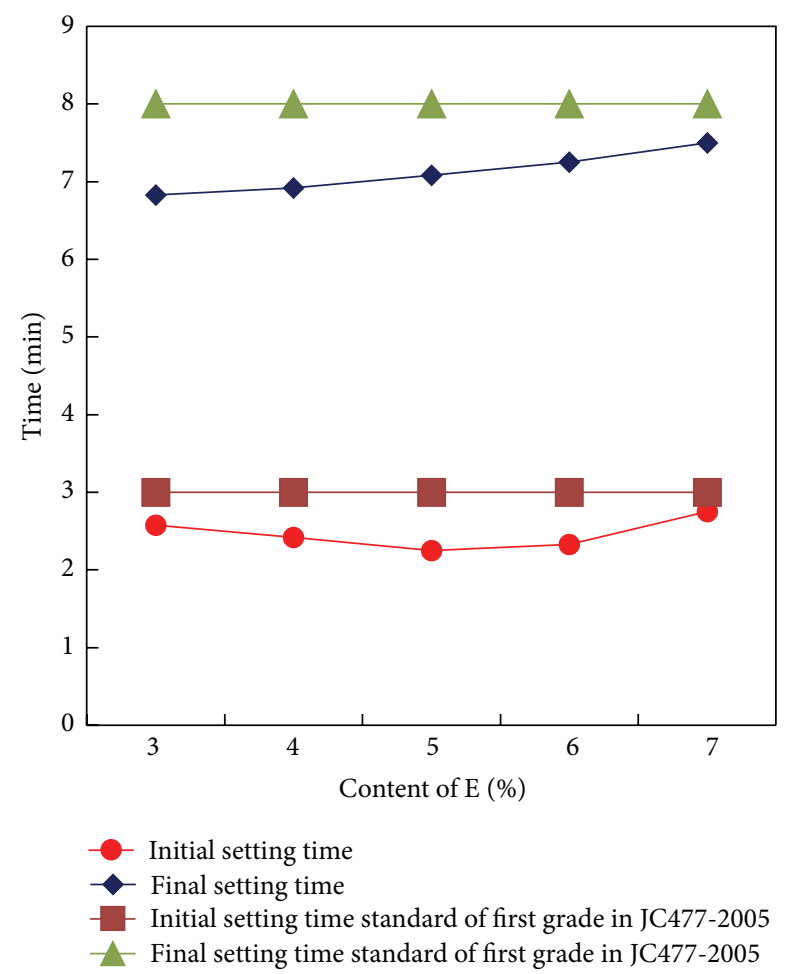

FIGURE 6: Setting time of cement grout mixing with modified mother liquor and Material E.

the modified mother liquor was combined with Material E is shown in Figure 6 and the freshly mixed cement grout after the accelerator liquid was added is shown in Figure 7.

It can be seen from the combination tests of the modified mother liquor with Material E that

(1) when the solution with E was added, the initial setting time of the cement grout did not vary significantly; with the increase of the content of $\mathrm{E}$, the initial setting time decreased and the minimum time was observed when the content of $\mathrm{E}$ was $5 \%$; when the content exceeded 5\%, the setting time increased; with the increase of the content of $\mathrm{E}$, the final setting time increased;

(2) during observation of these tests, Material E exhibited the effect of improving the viscosity of the solution; when added to the cement grout, the viscosity of the grout was further improved which was beneficial in reducing the material rebound of concrete during spraying process; in consideration of the effect of $E$ on the setting time, the density of addition was set as 5\% where the viscosity was the optimum and the setting time met the requirement of a first grade product.

4.3. Determination of the Formula for the New Liquid Accelerator. According to the reported experimental data, the final formula of the new liquid accelerator can be determined as shown in Table 11. The new liquid accelerator used in mines is named as WT-1 alkali-free liquid accelerator, referred to as WT-1 accelerator hereafter.

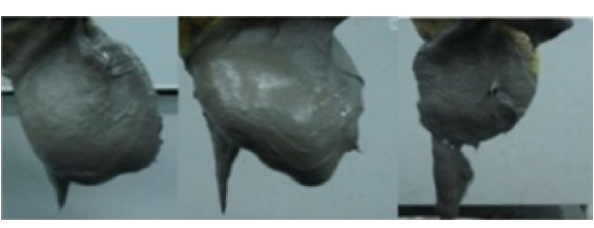

(a) Sample 1

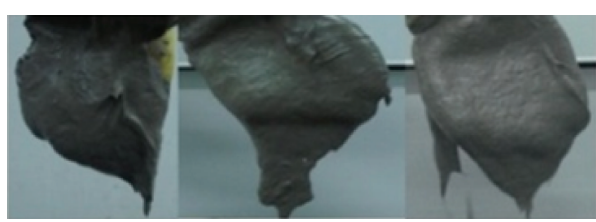

(b) Sample 2

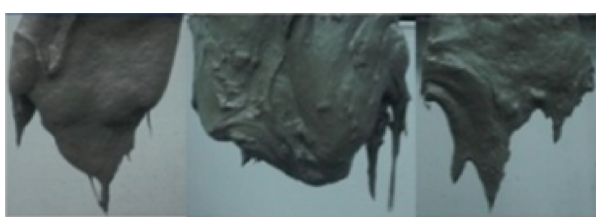

(c) Sample 3

Figure 7: New cement grout just added accelerator.

TABLE 11: Mass content of each component of WT-1 alkali-free liquid accelerator.

\begin{tabular}{lcccccc}
\hline Component & $\mathrm{A} / \%$ & $\mathrm{~B} / \%$ & $\mathrm{C} / \%$ & $\mathrm{D} / \%$ & $\mathrm{E} / \%$ & Water $\%$ \\
\hline $\begin{array}{l}\text { Mass content in } \\
\text { accelerator }\end{array}$ & 55 & 4 & 2.5 & 0.5 & 5 & 33 \\
$\begin{array}{l}\text { Mass content in } \\
\text { cement grout }\end{array}$ & 3.30 & 0.24 & 0.15 & 0.03 & 0.30 & 1.98 \\
\hline
\end{tabular}

\subsection{Measurement of the Performance of the New Liquid Accelerator}

4.4.1. Solid Content. Since the solid content of the accelerator affects the usage and performance, the solid content of the new accelerator was measured according to industrial standard of building material JC477-2005 Flashing Setting Admixtures for Shotcrete.

(1) Test Method. Place $10 \mathrm{~g} \pm 0.2 \mathrm{~g}$ of the sample into a clean and previous weighed flat weighting bottle, dry in vacuum until a constant weight is achieved, and then cool in a desiccator with silica gel to room temperature and weight the sample to $0.1 \mathrm{~g}$.

(2) Analysis of Test Results. The measured results of the solid content of the accelerator are shown in Table 12.

Industrial standard of building material JC477-2005 Flashing Setting Admixtures for Shotcrete provides that the solid content of accelerator should be less than the minimum control values of production plant. It can be seen from the measured results that the solid content of the new liquid accelerator was $60.5 \%$, less than the limit of $70 \%$ solid content of the vast majority of the production plant, meeting the requirement of the relevant China industry standard. 
TABLE 12: Measured results of the solid content of the accelerator.

\begin{tabular}{lccc}
\hline $\begin{array}{l}\text { Sample } \\
\text { mass/g }\end{array}$ & $\begin{array}{c}\text { Mass after } \\
\text { drying/g }\end{array}$ & $\begin{array}{c}\text { Solid } \\
\text { content/\% }\end{array}$ & $\begin{array}{c}\text { Average } \\
\text { solid } \\
\text { content/\% }\end{array}$ \\
\hline 10.1 & 6.2 & 61.4 & \\
9.9 & 6.1 & 61.6 & 60.9 \\
10.2 & 6.1 & 59.8 & \\
\hline
\end{tabular}

4.4.2. Adaptability Tests on the New Accelerator. In the experiment conditions outlined by JC477-2005 Flashing Setting Admixtures for Shotcrete, the adaptability of WT-1 accelerator with different types of cement was measured as shown in Table 13. Selected cements included the reference cement and wet spraying cement used in Xinjulong coal mine in Shandong province, Xin'an coal mine of Zaozhuang Mining Group, and Dongtan coal mine of Yankuang Group.

It could be concluded by comparative analysis about the measurement results of Table 13 and the industry standard that

(1) under the fixed conditions of $6 \%$ mixing content the initial setting time of WT-1 accelerator for different cements was less than $5 \mathrm{~min}$ and the final setting time was less than $12 \mathrm{~min}$, meeting the qualified requirement outlined in the national standard JC4772005 Flashing Setting Admixtures for Shotcrete; during reference cement tests, the initial setting time of WT-1 accelerator was less than $3 \mathrm{~min}$, and the final setting time was less than $8 \mathrm{~min}$, meeting the requirement of first grade product, which showed that the WT-1 accelerator had better adaptability to different cements;

(2) the order of the setting times from short to long is reference cement $42.5<$ normal Portland cement P.O42.5 < composite Portland cement P.C42.5 < composite Portland cement P.C32.5, which suggested that the setting time of higher grade cement is shorter than that of lower grade and the setting time of normal Portland cement is shorter than composite Portland cement. Therefore, it is recommended that the normal Portland cement with strength grade above 42.5 be used in wet spraying process in the mines.

4.4.3. Effect of the New Accelerator on the Cement Strength. In order to evaluate the effect of the WT-1 accelerator on the strength of cement, strength measurements were conducted on the reference cement and normal Portland cement P.O42.5 used for wet spraying in Xinjulong coal mines in Shandong. The reference cement was denoted as "JZ" and P.O42.5 normal Portland cement was denoted as "PT." The test results are shown in Table 14.

The test results revealed that the average compressive strength and compressive strength ratio of 28 days all satisfied the requirement detailed in the national standard when the content of addition was $6 \%$ whether "JZ" or "PT" cement. The compressive strength of the reference cement at 1 day and
28 days of cure was higher than that of the P.O42.5 normal Portland cement, but the difference was not significant.

\section{Field Application}

The established WT-1 accelerator was applied at an anchoring and shotcreting site in the belt roadway of the south wing of the Yankuang Group's Dongtan coal mine in Shandong province. A comparative analysis was conducted using a conventional GOR-I liquid accelerator in terms of rebound rate, dust concentration, and compressive strength of shotcrete. The site of wet spraying is shown in Figure 8.

5.1. Comparative Analysis of Rebound Rate. This process began with laying a plastic film on the bottom slab of the tunnel. Next, $0.5 \mathrm{~m}^{3}$ of concrete was sprayed onto the arch and the rebound material was collected, weighted, and calculated after spraying. The two sides of the tunnel were then sprayed with the same approach. The calculated results for rebound rate are shown in Table 15.

The data in Table 15 showed that

(1) the rebound rate of the material employing different accelerators was nonadded accelerator $>$ GOR-I accelerator $>$ WT-1 accelerator, which suggested that the two types of accelerators reduced the rebound rate of wet spraying concrete to different extents; in particular, the performance of the wet spraying concrete that lacked an accelerator did not meet the requirement outlined in national standard GB500862001 Specifications for Bolt-Shotcrete Support that the rebound rate at the sides should be less than $15 \%$ and for the arch less than 25\%;

(2) the average rebound rate of concrete with the addition of WT-1 accelerator was $9.5 \%$ and $5.4 \%$ less than that without and with the addition of GOR-I liquid accelerator, and WT-1 accelerator effectively reduced the amount of concrete rebound when shotcreting the arch and two sides; therefore, it appeared that the viscosity enhancement ingredients in the WT-1 accelerator improved the adhesion of the concrete and to the tunnel surface;

(3) the composition of WT-1 accelerator is noncorrosive and there were no reports of worker health or safety complaints; however, when using the GOR-I accelerator during shotcreting, particulates of the accelerator could be observed in the air and the accelerator mixed with the rebounded concrete was irritating, which caused skin burns of the workers.

5.2. Comparative Analysis of Dust Concentration. The filter weighing method was used to measure the accumulated dust. The sampling points for measuring the dust are shown in Figure 9 and the measured results are listed in Figures 10 and 11.

The data in Figures 10 and 11 showed that the WT-1 accelerator was superior to the GOR-I accelerator in preventing the generation of dust in the Dongtan coal mine. 
TABLE 13: Adaptability test of WT-1 type accelerator.

\begin{tabular}{lcccc}
\hline Cement kinds & Cement sources & $\begin{array}{c}\text { Content of } \\
\text { accelerator/\% }\end{array}$ & $\begin{array}{c}\text { Initial setting } \\
\text { time/min }\end{array}$ & $\begin{array}{c}\text { Final setting } \\
\text { time/min }\end{array}$ \\
\hline Reference cement 42.5 & Reference cement & 6 & 2.3 & 7.1 \\
Normal Portland cement P.O42.5 & Shandong Xinjulong coal mine & 6 & 3.1 & 7.7 \\
Composite Portland cement P.C32.5 & Xin'an coal mine of Zaokuang Group & 6 & 4.6 & 11.8 \\
Composite Portland cement P.C42.5 & Dongtan coal mine of Yankuang Group & 6 & 3.5 & 10.3 \\
\hline
\end{tabular}

TABLE 14: Effects of WT-1 type accelerator on the strength of cement paste.

\begin{tabular}{|c|c|c|c|c|c|}
\hline \multirow{2}{*}{$\begin{array}{l}\text { Test } \\
\text { number }\end{array}$} & \multirow{2}{*}{ Cement } & \multirow{2}{*}{ Content of accelerator $/ \%$} & \multicolumn{2}{|c|}{ Average compressive strength/MPa } & \multirow{2}{*}{$\begin{array}{l}\text { Compressive strength } \\
\text { ratio of } 28 \text { days/\% }\end{array}$} \\
\hline & & & $1 \mathrm{~d}$ & $28 \mathrm{~d}$ & \\
\hline 1 & $\mathrm{JZ}$ & \multirow{2}{*}{0} & 7.8 & 43.9 & 100 \\
\hline 2 & PT & & 7.2 & 43.1 & 100 \\
\hline 3 & $\mathrm{JZ}$ & \multirow{2}{*}{6} & 13.6 & 41.4 & 94.3 \\
\hline 4 & $\mathrm{PT}$ & & 12.5 & 40.2 & 93.3 \\
\hline
\end{tabular}

TABLE 15: Rebound rate of shotcrete.

\begin{tabular}{|c|c|c|c|}
\hline Accelerator & Position & $\begin{array}{c}\text { Rebound } \\
\text { rate/\% }\end{array}$ & $\begin{array}{c}\text { Average } \\
\text { rebound } \\
\text { rate } / \%\end{array}$ \\
\hline $\begin{array}{l}\text { Without adding } \\
\text { accelerator }\end{array}$ & $\begin{array}{c}\text { Arch } \\
\text { Two sides }\end{array}$ & $\begin{array}{l}26.2 \\
15.5\end{array}$ & 20.9 \\
\hline WT-1 type accelerator & $\begin{array}{c}\text { Arch } \\
\text { Two sides }\end{array}$ & $\begin{array}{c}13.3 \\
9.4\end{array}$ & 11.4 \\
\hline GOR-I type accelerator & $\begin{array}{c}\text { Arch } \\
\text { Two sides }\end{array}$ & $\begin{array}{l}21.3 \\
12.2 \\
\end{array}$ & 16.8 \\
\hline
\end{tabular}

The WT-1 accelerator achieved better dust prevention effects, validating the contribution of viscosity enhancement by the select ingredients in the accelerator. The improved viscosity captures the particulates of concrete and agglomerates them which further reduces dust concentration at the site of wet spraying. The average total dust density in the entire anchoring and shotcreting site was reduced from $13.08 \mathrm{mg} / \mathrm{m}^{3}$ in the case of nonadded accelerator and $7.95 \mathrm{mg} / \mathrm{m}^{3}$ in the case of GOR-I accelerator to $2.47 \mathrm{mg} / \mathrm{m}^{3}$ using the WT-1 accelerator. The average inhalable dust concentration reduced from $6.28 \mathrm{mg} / \mathrm{m}^{3}$ and $3.93 \mathrm{mg} / \mathrm{m}^{3}$ to $1.10 \mathrm{mg} / \mathrm{m}^{3}$.

5.3. Comparative Analysis of Compressive Strength of Shotcrete. The compressive strength of the shotcrete was measured according to national standard GB50086-2001 Specifications for Bolt-Shotcrete Support. The compressive strength after 28 days of curing was tested and listed in Table 16.

As can be seen from the data in Table 16

(1) when the accelerator was included in the shotcrete, the compressive strength at the 28-day cure generally decreased; the 28-day cure strength loss of the high alkalinity GOR-1 accelerator exceeded $25 \%$ and the requirements of first grade product outlined in JC477-2005 Flashing Setting Admixtures for Shotcrete were not met but it was still a qualified product; however, the WT-1 accelerator had a compressive strength ratio at 28 days that was $90.1 \%$ which far exceeded the requirement of first grade product which was $75 \%$; moreover, regardless of the type of accelerator added, the 28-day strength of the concrete met the requirements of $20 \mathrm{MPa}$ outlined in GB50086-2001 Specifications for Bolt-Shotcrete Support; there were no failed cases and the effect of wet spraying support was outstanding;

(2) the strength of concrete mixed in the lab was normally much higher than that of shotcrete large slabs for two reasons; first, the methods of fabrication are different; the lab specimens were hand spaded, while, in the mine, the concrete was blown into precast moulds using compressed air; as a result, the onsite samples were less compact than the lab samples, and the onsite concrete is not as evenly blended as the lab concrete.

\section{Conclusions}

(1) Experimental analysis of the primary factors affecting the performance of liquid accelerators yielded the following conclusions. Different mixing time significantly affects the setting time. When the mixing time was about 8 seconds, the setting time was the shortest, so it was the optimum mixing time selected in this experimental study. When compared with mixing time, concrete vibration frequency has less of an effect on the setting time and the coagulating effect was the best when the vibration frequency was 5 . A better coagulating effect could be achieved when the content of the accelerator was about $6 \%$. The setting time of the concrete decreases with the increase of temperature of material.

(2) Extensive preliminary experimental testing resulted in the selection of five materials to develop a new type of liquid accelerator for shotcreting in mines. These are as follows. Material A is aluminum sulfate 
TABLE 16: Testing results of compressive strength about sprayed concrete.

\begin{tabular}{|c|c|c|c|c|c|}
\hline Accelerator & \multicolumn{3}{|c|}{ Compressive strength of 28 days/MPa } & Average strength $/ \mathrm{MPa}$ & $\begin{array}{l}\text { Compressive strength } \\
\text { ratio of } 28 \text { days } \% \%\end{array}$ \\
\hline \multirow{2}{*}{ Without adding accelerator } & 38.2 & 37.7 & 35.8 & \multirow{2}{*}{37.9} & \multirow{2}{*}{100} \\
\hline & 39.9 & 38.0 & 37.7 & & \\
\hline \multirow{2}{*}{ WT-1 type accelerator } & 35.8 & 31.2 & 36.1 & \multirow{2}{*}{33.8} & \multirow{2}{*}{89.2} \\
\hline & 32.0 & 34.9 & 32.9 & & \\
\hline \multirow{2}{*}{ GOR-I type accelerator } & 26.7 & 27.4 & 26.5 & \multirow{2}{*}{27.8} & \multirow{2}{*}{73.5} \\
\hline & 30.1 & 28.8 & 27.5 & & \\
\hline
\end{tabular}
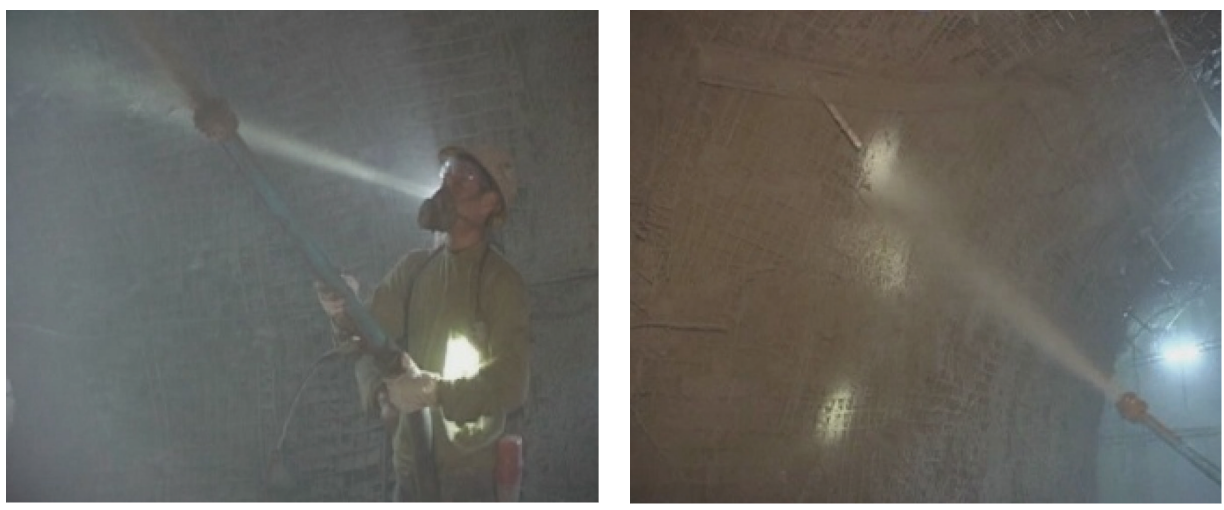

FIGURE 8: The site of wet spraying.

octadecahydrate which is the main coagulating constituent of the new accelerator and it contains 51.4\% of anhydrous aluminum sulfate. Material B is sodium fluoride, $\mathrm{C}$ is triethanolamine, $\mathrm{D}$ is polyacrylamide, and $\mathrm{E}$ is bentonite. According to the single-admixture experiment of $\mathrm{A}$, combination tests of $\mathrm{A}$ with $\mathrm{B}$ and $\mathrm{C}$ were conducted, respectively, orthogonal matching tests for A, B, and C were carried out, and the formula of the mother liquor for the accelerator was determined. By the combination tests of mother liquor with the accelerator with D and E, WT-1 alkali-free liquid accelerator was developed; the quality content of each component was Material A: 55\%; Material B: 4\%; Material C: $2.5 \%$; Material D: 0.5\%; Material E: $5 \%$, and the water is $33 \%$. According to the fact that the content of accelerator in the cement is $6 \%$, the content ratios relative to the cement of $\mathrm{A}, \mathrm{B}, \mathrm{C}, \mathrm{D}$, and $\mathrm{E}$ and the water are $3.3 \%, 0.24 \%, 0.15 \%, 0.03 \%, 0.3 \%$, and $1.98 \%$.

(3) The performance of WT-1 accelerator was measured according to JC477-2005 Flashing Setting Admixtures for Shotcrete and GB50086-2001 Specifications for Bolt-Shotcrete Support. Test results showed that the adaptability of WT-1 accelerator with different types of cement that were described in this paper is outstanding. When the content of the accelerator is $6 \%$, measured by the reference cement which was described in this paper, the initial setting time is 2 minutes and 15 seconds and the final setting time is 7 minutes and 5 seconds. The compressive strength after 1 day of curing is $13.6 \mathrm{MPa}$ and strength ratio after 28 days of curing is $94.8 \%$, which meet the requirement of a first grade product. The field application in an anchoring and shotcreting site at the Dongtan coal mine showed that WT-1 accelerator outperformed conventional accelerators in terms of rebound rate, dust concentration, and compressive strength of shotcrete.

\section{Conflict of Interests}

The authors declare that there is no conflict of interests regarding the publication of this paper.

\section{Acknowledgments}

This work was financially supported by State Key Program of National Natural Science of China (Grant no. U1261205); National Natural Science Foundation of China (Grant nos. 51474139, 51204103, and 51404147); SDUST Research Fund (Grant no. 2014JQJH106); China Postdoctoral Science Foundation (2015M570602); Open Fund of the State Key Laboratory of Mining Disaster Prevention and Control CoFounded by Shandong Province and the Ministry of Science and Technology (Grant no. MDPC2013KF13); Open Fund of the Key Laboratory of Safety and High-Efficiency Coal Mining, Ministry of Education (Anhui University of Science and Technology, Grant no. JYBSYS2014105); Science and Technology Project of Huangdao District, Qingdao (Grant no. 2014-1-30); Joint Innovative Center for Safe and Effective Mining Technology and Equipment of Coal Resources of Shandong Province; Shandong Province "Taishan Scholar" 


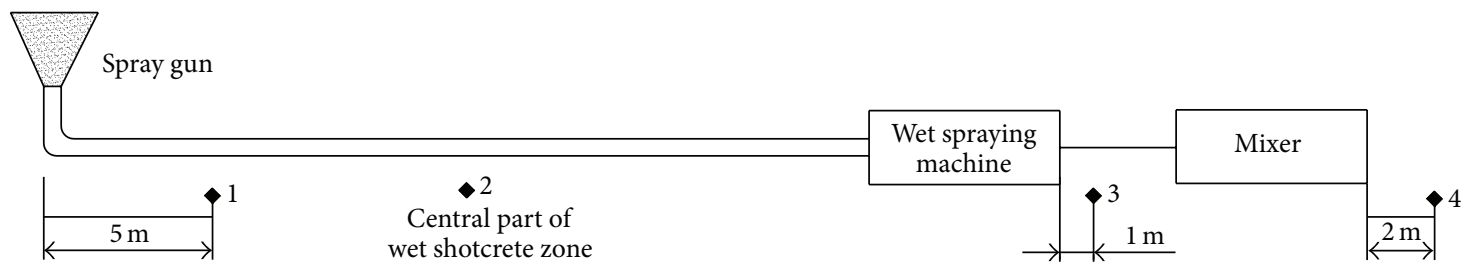

FIGURE 9: The sampling points for measuring the dust.

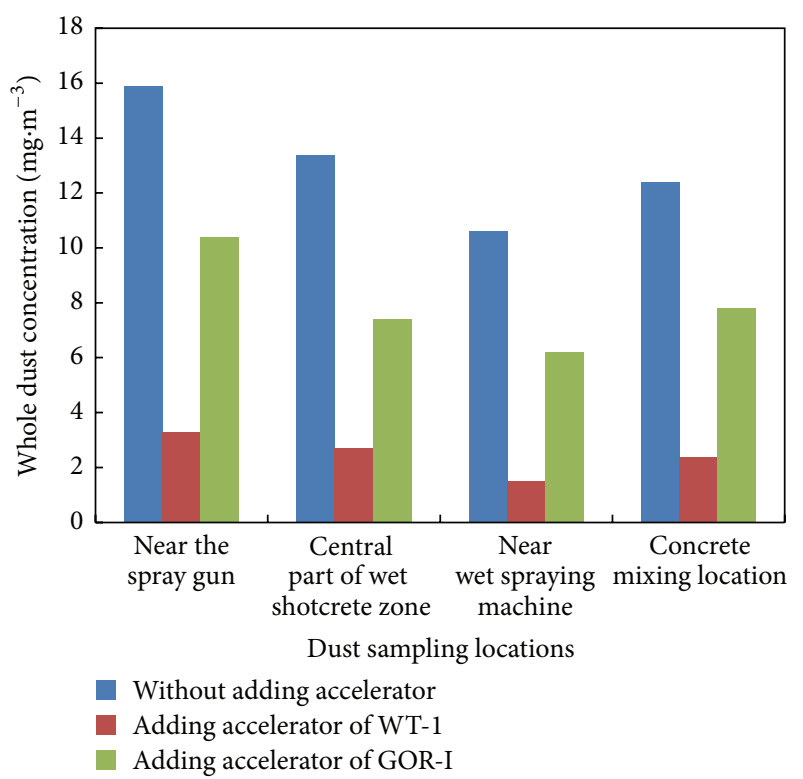

Figure 10: Comparison chart of whole dust concentration.

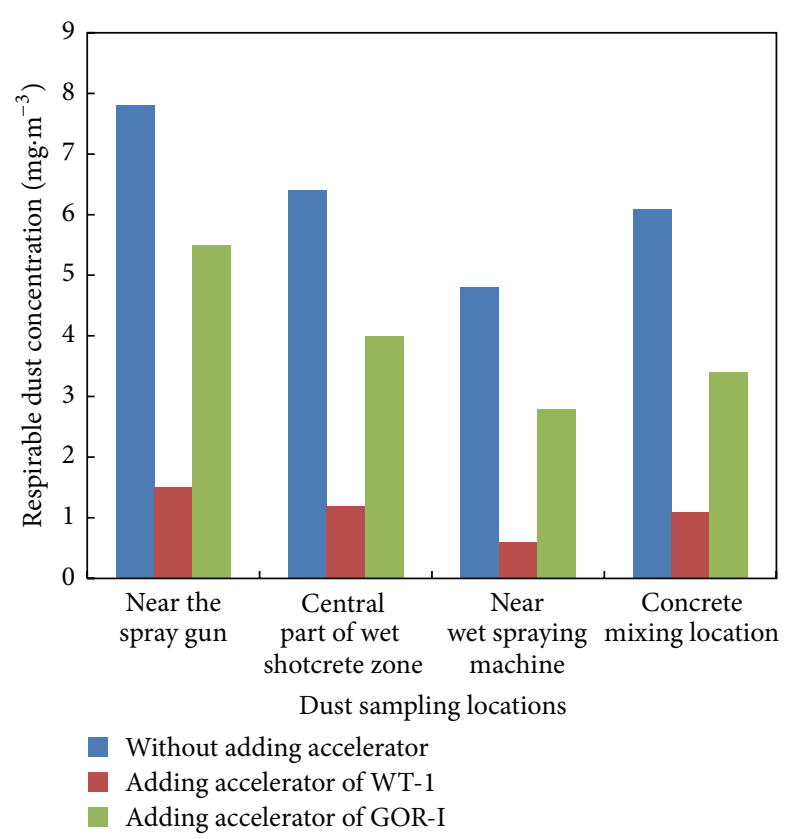

FIgURE 11: Comparison chart of respirable dust concentration.
Project Fund; The Key Technology Projects of Chinese State Administration of Work Safety for Preventing Major Safety Production Accidents (Shandong-0083-2015AQ).

\section{References}

[1] D. Liu, J. Zhao, J. Wei, and X. Ding, "Study on adaptability state alkali-free setting-accelerator," Bulletin of the Chinese Ceramic Society, vol. 41, no. 9, pp. 1822-1831, 2013.

[2] J. Stark, "Recent advances in the field of cement hydration and microstructure analysis," Cement and Concrete Research, vol. 41, no. 7, pp. 666-678, 2011.

[3] R. Yang, T. Xiao, B. Liu, and X. Niu, "Application and development of spurting concrete rapid setting admixture," China Mining Magazine, vol. 14, no. 7, pp. 79-81, 2005.

[4] T.-B. Min, I.-S. Cho, W.-J. Park, H.-K. Choi, and H.-S. Lee, "Experimental study on the development of compressive strength of early concrete age using calcium-based hardening accelerator and high early strength cement," Construction and Building Materials, vol. 64, pp. 208-214, 2014.

[5] A. A. A. Hassan, A. A. Abouhussien, and J. Mayo, "The use of silica-breccia as a supplementary cementing material in mortar and concrete," Construction and Building Materials, vol. 51, pp. 321-328, 2014.

[6] J.-P. Won, B.-R. Choi, and J.-W. Lee, "Experimental and statistical analysis of the alkali-silica reaction of accelerating admixtures in shotcrete," Construction and Building Materials, vol. 30, pp. 330-339, 2012.

[7] J. Pickelmann and J. Plank, "A mechanistic study explaining the synergistic viscosity increase obtained from polyethylene oxide (PEO) and $\beta$-naphthalene sulfonate (BNS) in shotcrete," Cement and Concrete Research, vol. 42, no. 11, pp. 1409-1416, 2012.

[8] J. Cheung, A. Jeknavorian, L. Roberts, and D. Silva, "Impact of admixtures on the hydration kinetics of Portland cement," Cement and Concrete Research, vol. 41, no. 12, pp. 1289-1309, 2011.

[9] Z. Pan and J. Cheng, "Research status and development trend of accelerating agent," Mine Construction Technology, vol. 26, no. 2, pp. 22-27, 2005.

[10] W. Lv, F. Li, and Z. Pan, "Improvement of the alkali-free cement setting accelerator and its acceleration mechanism," Journal of Nanjing University of Technology, vol. 29, no. 2, pp. 34-39, 2007.

[11] G. Xiao, Study on the liquid alkali-free accelerator [M.S. thesis], Hunan University, Changsha, China, 2011.

[12] J. Cheng, Study on synthesis of liquid state alkali-free setting accelerator for Portland cement [M.S. thesis], Nanjing University of Technology, Nanjing, China, 2005.

[13] Z. Pan, W. Lv, and J. Cheng, "Properties of the alkali-free liquid cement accelerator and its acceleration mechanism," Mine Construction Technology, vol. 27, no. 5, pp. 25-29, 2006. 
[14] Z. Pan, F. Li, and W. Lv, "Properties of liquid state low alkaline accelerator for Portland cement and its mechanism of acceleration," Chemical Building Materials, vol. 24, no. 2, pp. 3943, 2008.

[15] X. Ding, S. Zhao, Y. Wang, and Y. Liang, "Study on a liquid setting-accelerator free-from alkali," Concrete, no. 4, pp. 77-78, 2005.

[16] Z. Zhang, X. Ding, Y. Pan, and J. Wei, "Performance and action mechanism of alkali-free liquid accelerating agent," Concrete, no. 1, pp. 71-74, 2011.

[17] Y. Han, B. Jiang, and J. Yang, "Development of JL-1 non-alkaline liquid accelerator of shotcrete," Concrete, no. 4, pp. 75-76, 2009.

[18] Q. Bo, Y. Lei, D. Wen et al., "Research of a low-alkali liquid accelerating agent with its formulation and properties," The World of Building Materials, vol. 34, no. 5, pp. 10-12, 2013.

[19] R. Yang, T. Xiao, and B. Liu, "Analysis of strengthening mechanism of RSD rapid setting admixture," Journal of China University of Mining and Technology, vol. 35, no. 2, pp. 153-156, 2006.

[20] B. Felekoğlu, K. Tosun, and B. Baradan, "Compatibility of a polycarboxylate-based superplasticiser with different setcontrolling admixtures," Construction and Building Materials, vol. 25, no. 3, pp. 1466-1473, 2011.

[21] W. Zhao, Y. Tan, Y. Shang, and J. Duan, "Themechanism analysis of shotcrete concrete additive used in coal mines," Journal of China Coal Society, vol. 34, no. 4, pp. 526-530, 2009.

[22] C. Paglia, F. Wombacher, and H. Böhni, "The influence of alkali-free and alkaline shotcrete accelerators within cement systems: I. Characterization of the setting behavior," Cement and Concrete Research, vol. 31, no. 6, pp. 913-918, 2001.

[23] C. Paglia, F. Wombacher, and H. Böhni, "The influence of alkalifree and alkaline shotcrete accelerators within cement systems: influence of the temperature on the sulfate attack mechanisms and damage," Cement and Concrete Research, vol. 33, no. 3, pp. 387-395, 2003.

[24] C. Maltese, C. Pistolesi, A. Bravo, F. Cella, T. Cerulli, and D. Salvioni, "Effects of setting regulators on the efficiency of an inorganic acid based alkali-free accelerator reacting with a Portland cement," Cement and Concrete Research, vol. 37, no. 4, pp. 528-536, 2007.

[25] C. Maltese, C. Pistolesi, A. Bravo, F. Cella, T. Cerulli, and D. Salvioni, "A case history: effect of moisture on the setting behaviour of a Portland cement reacting with an alkali-free accelerator," Cement and Concrete Research, vol. 37, no. 6, pp. 856-865, 2007.

[26] N. Varley, "Experiences with the use of alkali free accelerators in Asia," Tunnelling and Underground Space Technology, vol. 21, no. 3-4, p. 409, 2006.

[27] J.-P. Won, U.-J. Hwang, C.-K. Kim, and S.-J. Lee, "Mechanical performance of shotcrete made with a high-strength cementbased mineral accelerator," Construction and Building Materials, vol. 49, pp. 175-183, 2013.

[28] S. Jeon, K. You, B. Park, and H.-G. Park, "Evaluation of support characteristics of wet-mixed shotcrete with powder type cement mineral accelerator," Tunnelling and Underground Space Technology, vol. 21, no. 3-4, pp. 425-426, 2006.

[29] H.-G. Park, S.-K. Sung, C.-G. Park, and J.-P. Won, "Influence of a $\mathrm{C}_{12} \mathrm{~A}_{7}$ mineral-based accelerator on the strength and durability of shotcrete," Cement and Concrete Research, vol. 38, no. 3, pp. 379-385, 2008. 

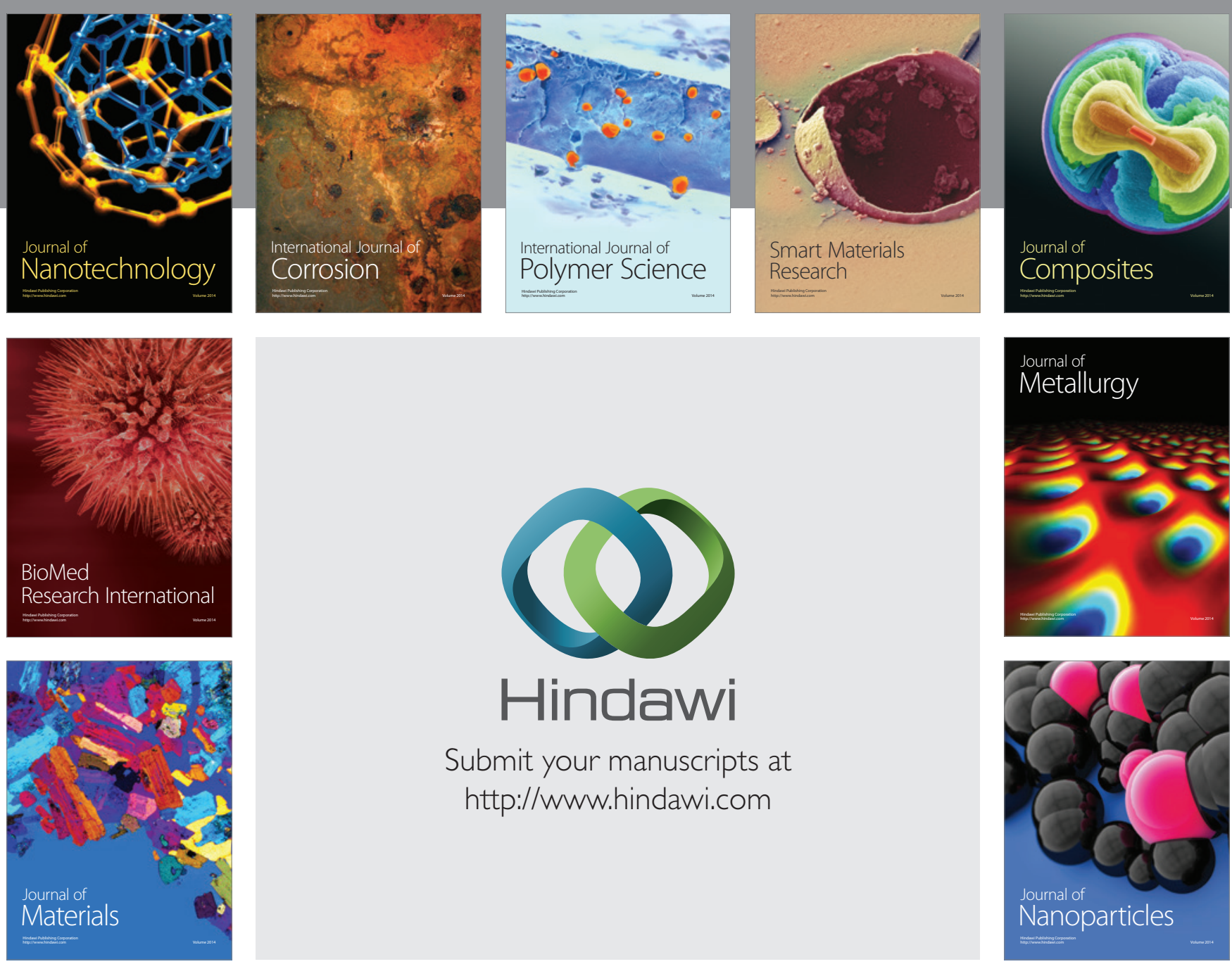

Submit your manuscripts at http://www.hindawi.com
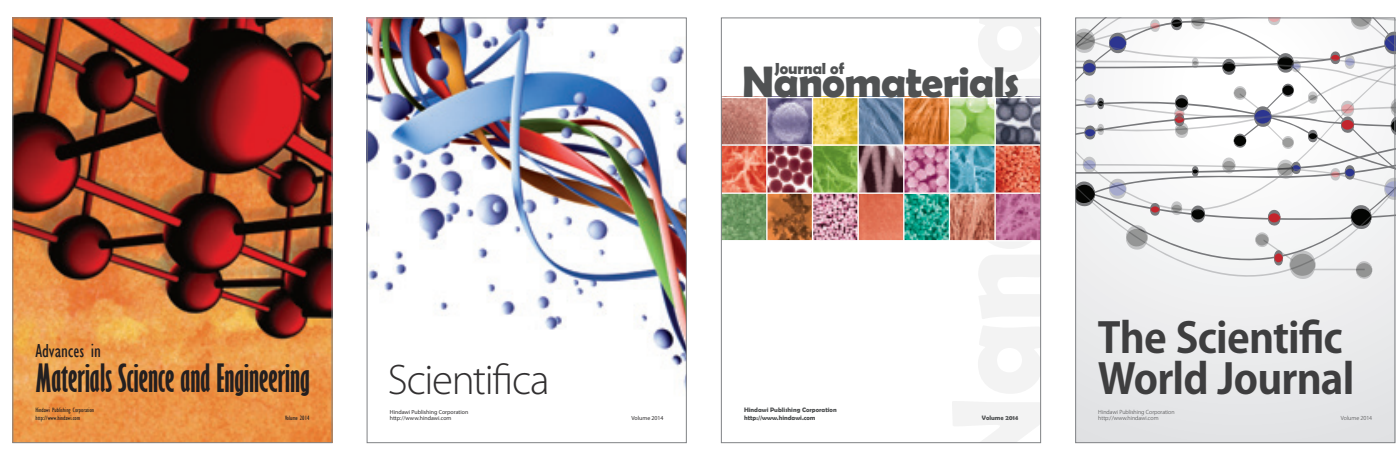

\section{The Scientific World Journal}
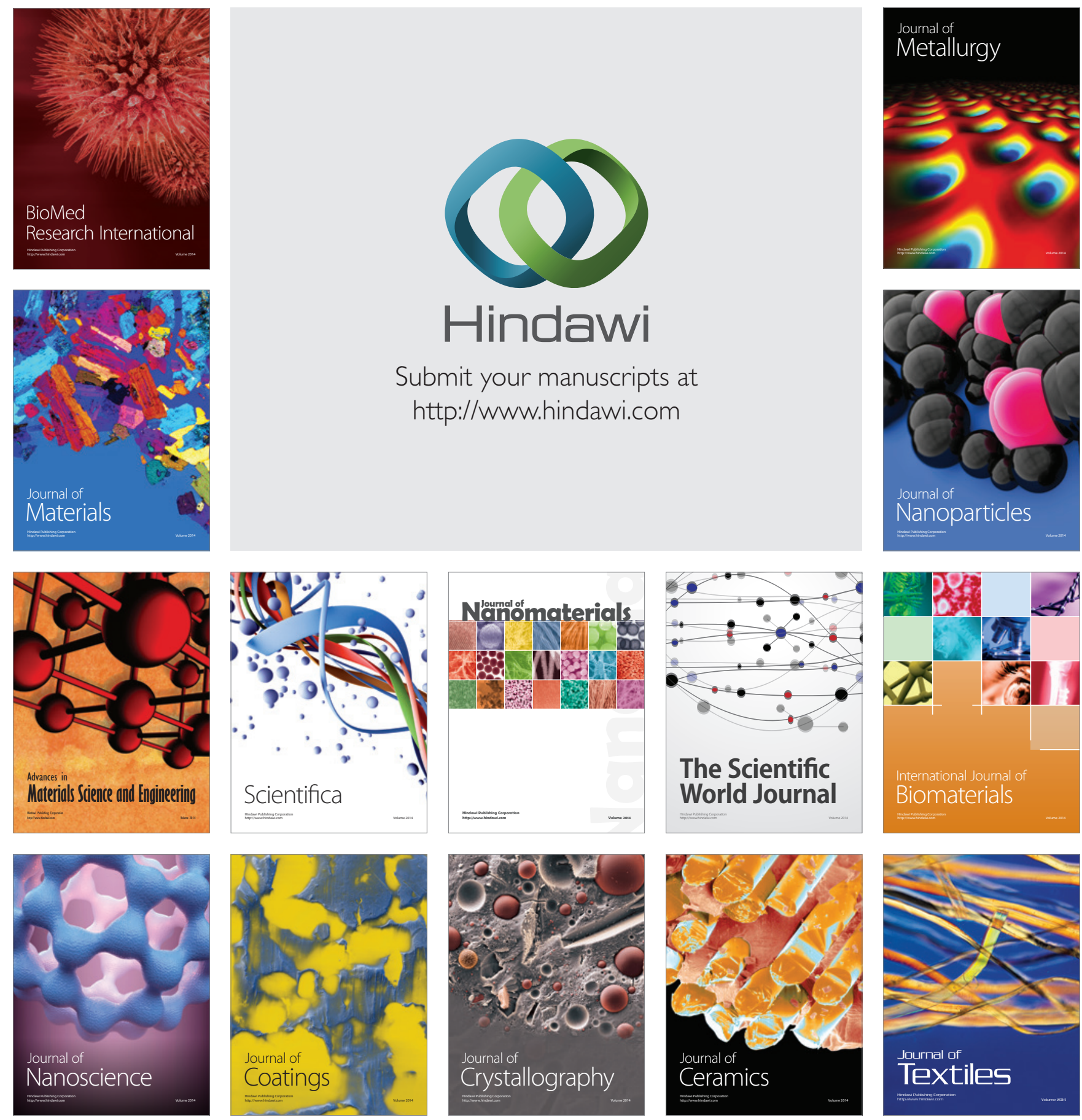